\title{
A longitudinal twin and sibling study of the hopelessness theory of depression in adolescence and young adulthood
}

\author{
M. A. Waszczuk ${ }^{1,2}$, A. E. Coulson ${ }^{1}$, A. M. Gregory ${ }^{3}$ and T. C. Eley ${ }^{1 *}$ \\ ${ }^{1}$ King's College London, MRC Social, Genetic and Developmental Psychiatry Centre, Institute of Psychiatry, Psychology and Neuroscience, \\ London, UK \\ ${ }^{2}$ Department of Psychiatry, State University of New York at Stony Brook, Stony Brook, NY, USA \\ ${ }^{3}$ Department of Psychology, Goldsmiths, University of London, London, UK
}

\begin{abstract}
Background. Maladaptive cognitive biases such as negative attributional style and hopelessness have been implicated in the development and maintenance of depression. According to the hopelessness theory of depression, hopelessness mediates the association between attributional style and depression. The aetiological processes underpinning this influential theory remain unknown. The current study investigated genetic and environmental influences on hopelessness and its concurrent and longitudinal associations with attributional style and depression across adolescence and emerging adulthood. Furthermore, given high co-morbidity between depression and anxiety, the study investigated whether these maladaptive cognitions constitute transdiagnostic cognitive content common to both internalizing symptoms.
\end{abstract}

Method. A total of 2619 twins/siblings reported attributional style (mean age 15 and 17 years), hopelessness (mean age 17 years), and depression and anxiety symptoms (mean age 17 and 20 years).

Results. Partial correlations revealed that attributional style and hopelessness were uniquely associated with depression but not anxiety symptoms. Hopelessness partially mediated the relationship between attributional style and depression. Hopelessness was moderately heritable ( $\mathrm{A}=0.37,95 \%$ confidence interval $0.28-0.47$ ), with remaining variance accounted for by non-shared environmental influences. Independent pathway models indicated that a set of common genetic influences largely accounted for the association between attributional style, hopelessness and depression symptoms, both concurrently and across development.

Conclusions. The results provide novel evidence that associations between attributional style, hopelessness and depression symptoms are largely due to shared genetic liability, suggesting developmentally stable biological pathways underpinning the hopelessness theory of depression. Both attributional style and hopelessness constituted unique cognitive content in depression. The results inform molecular genetics research and cognitive treatment approaches.

Received 17 November 2015; Revised 15 February 2016; Accepted 23 February 2016; First published online 28 March 2016

Key words: Adolescence, attributional style, cognitive specificity, depression, development, genes, hopelessness, twin study.

\section{Introduction}

Depression is very common, chronic, and increases markedly in adolescence (Costello et al. 2003; Ford et al. 2003; Hankin et al. 1998). Adolescent depression reliably predicts long-term mental health difficulties (Harrington et al. 1990; Dunn \& Goodyer, 2006; Gregory et al. 2007) and carries burden of social and educational impairment (Puig-Antich et al. 1993; Katon et al. 2010; Riglin et al. 2014). Maladaptive

* Address for correspondence: Prof T. C. Eley, MRC Social, Genetic and Developmental Psychiatry Centre, Institute of Psychiatry,

Psychology and Neuroscience, King's College London, Box PO80, De Crespigny Park, London SE5 8AF, UK.

(Email: thalia.eley@kcl.ac.uk) cognitions, such as biases in how individuals attend to, interpret and remember emotional information, have been implicated in the development and maintenance of depression (Jacobs et al. 2008), and are targeted by recommended first-line treatments such as cognitive behavioural therapy (CBT) (AACAP, 2007). Therefore, it is of high importance to understand the aetiology of depression-related cognitions operating across adolescence and emerging adulthood.

\section{Hopelessness theory of depression}

Negative attributional style and hopelessness are two maladaptive cognitions associated with adolescent depression. Negative attributional style refers to the attribution of negative events to internal (directed to the

This is an Open Access article, distributed under the terms of the Creative Commons Attribution licence (http://creativecommons.org/licenses/by/4.0/), which permits unrestricted re-use, distribution, and reproduction in any medium, provided the original work is properly cited. 
self), stable (likely to persist over time) and global (likely to affect many aspects of life) causes, and positive events to external, unstable and specific causes (Abramson et al. 1978). Hopelessness is an expectation that the future will be negative and that this outcome cannot be altered (Beck et al. 1974). A number of theories specified negative attributional style and hopelessness as causal cognitive vulnerabilities in depression, including the hopelessness theory of depression (Abramson et al. 1989). Specifically, the theory posits that in the context of negative life events, attributional style contributes to the formation of hopelessness, which in turn contributes to development of depression symptoms. In other words, hopelessness is thought to mediate the prospective relationship between attributional style and depression. Although to date many aspects of the theory have gained empirical support (Metalsky \& Joiner, 1992; Joiner, 2001; Hankin, 2008), evidence for the mediation is mixed in both child and adult samples (Alloy \& Clements, 1998; Abela, 2001; Hankin et al. 2001).

\section{Cognitive specificity}

Given high co-morbidity of depression with anxiety disorders (Angold et al. 1999; Costello et al. 2003; Kessler et al. 2005; Cummings et al. 2014), it is of theoretical and clinical interest to differentiate them based on maladaptive cognitions. The cognitive content hypothesis posits that although anxious and depressed individuals both have distorted cognitions, the content differs across these disorders (Beck \& Perkins, 2001). Specifically, it is hypothesized that depressed individuals tend to think negatively about the self and focus on experiences of loss whereas anxious individuals focus on perceived threat or danger. In line with this model, cognitive concerns targeted in CBT tend to vary across anxiety and depressive disorders (Brewin, 1996).

The hopelessness theory of depression has been proposed specifically to explain some of the causal factors in depression. In support of this claim, evidence generally suggests that hopelessness is uniquely associated with depression and not anxiety (Alloy \& Clements, 1998; Beck et al. 2001, 2006; Miranda \& Mennin, 2007; Alloy et al. 2012; Hendriks et al. 2014). This indicates that negative inferences about the future might constitute unique content in depression that differentiates it from anxiety disorders. However, there is mixed evidence about the specificity of negative attributional style to depression (Ahrens \& Haaga, 1993; Luten et al. 1997; Waschbusch et al. 2003; Hankin et al. 2004; Brozina \& Abela, 2006; Reardon \& Williams, 2007), suggesting that maladaptive interpretations of events might instead be a transdiagnostic cognitive risk factor for internalizing problems. Notably, the specificity of attributional style and hopelessness has largely been studied in adults. As maladaptive cognitions are thought to emerge in development (Cole et al. 2008; Field \& Lester, 2010), it is important to gain a better understanding of disorder-specific and transdiagnostic cognitions in depression and anxiety in young people.

\section{Aetiology}

There is growing evidence that individual differences in maladaptive cognitions stem from both genetic and environmental influences. Our team has previously shown that attributional style is moderately heritable in adolescence (Lau et al. 2006; Lau \& Eley, 2008; Zavos et al. 2010). These studies have also found genetic and environmental overlap between attributional style, depression and anxiety symptoms, suggesting that maladaptive cognitive processes in part represent a genetic vulnerability to internalizing problems, in addition to being reflections of the individual's environment (Beck, 2008). This also indicates that both inherited predispositions and environmental circumstances might play a role in the hopelessness theory of depression, an idea originally hypothesized by Abramson et al. (1989). To date, a composite measure of hopelessness and guilt was found to be moderately heritable in adults, with substantial influence of the individual-specific environment (Jang et al. 2004), however no study has yet investigated the aetiology of hopelessness in young people, or its genetic and environmental associations with depression or attributional style. Examining aetiological influences on the joint associations between attributional style, hopelessness and depression could help to clarify some of the mechanisms that underpin these relationships in the hopelessness theory of depression. It may also help to disentangle common and specific influences on these traits.

\section{Aims}

The current study investigated the hopelessness theory of depression from an aetiological perspective. Three waves of data from a large epidemiological sample of adolescent twins and siblings were employed. First, the potential cognitive specificity of negative attributional style and hopelessness to depression $v$. anxiety symptoms was investigated, both concurrently at mean age 17 years, and prospectively across adolescence and young adulthood. Based on the existing, largely adult literature we hypothesized that hopelessness would be uniquely associated with depression while attributional style would be associated with both depression and anxiety. Second, we aimed to determine whether hopelessness mediates the 
relationship between attributional style and depression, both concurrently and across time. In line with the hopelessness theory of depression, we expected to observe at least partial mediation. Third, we explored what proportion of variance in hopelessness was accounted for by genetic and environmental influences. We hypothesized that similarly to attributional style, hopelessness would be moderately heritable, in line with adult estimates of hopelessness and guilt. Fourth, we examined the shared aetiology between attributional style, hopelessness and depression. We expected that common genetic influences would explain most of the shared variance between these three traits, in line with the generalist genes hypothesis (Eley, 1997), which proposes that traits co-vary due to shared genetic influences, while non-shared environmental influences are generally symptom-specific and contribute to the differentiation between the traits. Based on the generalist genes hypothesis, we hypothesized that there would be no unique genetic association between hopelessness and depression independent of attributional style.

\section{Method}

\section{Sample}

We used data from waves 2-4 (hereon referred to as times 1-3, respectively) of a longitudinal twin and sibling study, the Genesis 1219 (G1219; McAdams et al. 2013). The study was given ethical approval by the Research Ethics Committee of the Institute of Psychiatry, King's College, London, South London and Maudsley NHS Trust and Goldsmiths, University of London. Informed consent was obtained from parents of adolescents aged $<16$ years and from participants aged $\geqslant 16$ years. The sample characteristics are presented in Table 1. Concurrent analyses were conducted at time 2 , the only time at which hopelessness was measured. Longitudinal analyses spanned times 1-3, using attributional style measure at time 1 , hopelessness at time 2 and depression and anxiety symptoms at time 3 .

\section{Measures}

\section{Attributional style (times 1 and 2)}

Participants completed the revised Children's Attributional Style Questionnaire (Thompson et al. 1998); a 24-item forced-choice questionnaire that described a positive or negative event (e.g. 'You get an $\mathrm{A}$ on a test') and asked about its possible cause (e.g. 'I am clever'). The measure assesses three dimensions of attributional style (internal-external, globalspecific, stable-unstable), with an overall lower composite score indicating more negative attributional style. The measure demonstrates moderate internal consistency reliabilities ranging $\alpha=0.40-0.60$, moderate 6-month test-retest reliability of 0.53 and small to moderate criterion-related validity assessed through association with depression symptoms $(r=-0.40)$ (Thompson et al. 1998).

\section{Hopelessness (time 2)}

Participants completed the Hopelessness Scale (Beck et al. 1974), consisting of 20 true-false items assessing feelings of hopelessness (e.g. 'My future seems dark to $\left.\mathrm{me}^{\prime}\right)$. Theories of hopelessness suggest that it may be underpinned by three subfactors reflecting feelings about the future, loss of motivation and future expectations (Beck et al. 1974), although unidimensional solutions have also been reported (Dozois \& Covin, 2004). In the current analyses items were summed to create a total score. The measure has sound psychometric properties in both clinical and healthy adults and adolescent samples, with high internal consistencies up to $\alpha=0.90$ and high 3 -week test-retest reliability of 0.85 , demonstrating robust validity with related constructs, such as depression symptoms, and suicidal ideation and intent independently of depression (Beck et al. 1974; Young et al. 1992; Dozois \& Covin, 2004).

\section{Depression symptoms (times 2 and 3)}

Participants completed the Short Mood and Feelings Questionnaire (Angold et al. 1995), a 13-item unidimensional self-report measure assessing how often depression symptoms occurred in the past 2 weeks. Responses were summed to give a total depression score. The measure demonstrates good reliability and validity (Angold et al. 1995).

\section{Anxiety symptoms (times 2 and 3)}

At time 2 adolescents completed the Spence Children's Anxiety Scale (Spence, 1998); a 38-item self-report questionnaire tapping anxiety disorder related symptoms, such as generalized anxiety, panic, separation anxiety and social anxiety symptoms. At time 3 participants completed the Revised Symptoms of Anxiety Scale (Gregory et al. 2011), an age-appropriate version of the Revised Child Anxiety and Depression Scale (Chorpita et al. 2000), consisting of 36 self-report items designed to assess DSM-IV anxiety disorder symptoms. Responses were summed to create total scores. The measures have good reliability and validity (Spence, 1998; Birmaher et al. 1999; Chorpita et al. 2000; Gregory et al. 2011). Internal consistencies for all measures in the current study and descriptive statistics are presented in Table 2. 
Table 1. Sample characteristics

\begin{tabular}{llll}
\hline & Time 1 & Time 2 & Time 3 \\
\hline No. of pairs & 1372 & 866 & 896 \\
Female/male pairs (\%) & $768(56) / 604(44)$ & $520(60) / 346(40)$ & $547(61) / 349(39)$ \\
Age: mean (years, months) (range) & $15.0(12.0-21.0)$ & $17.0(14.0-23.0)$ & $20.0(18.0-27.0)$ \\
Zygosity (MZ/DZS/DZO/sib/unknown) & $350 / 313 / 334 / 330 / 45$ & $234 / 207 / 232 / 182 / 11$ & $230 / 214 / 232 / 201 / 19$ \\
\hline
\end{tabular}

MZ, Monozygotic; DZS, dizygotic same sex; DZO, dizygotic opposite sex.

The inclusion of siblings inevitably resulted in large age ranges; however $72 \%$ of the participants were twins with a tighter age range (e.g. at time 2, age S.D. $=1.11$, range $=15-19$ for twins, age S.D. $=1.97$, range $=15-23$ for siblings).

Attrition was predicted by socio-economic status (responses were more likely from individuals with parents reporting higher qualifications and home ownership), delinquency (individuals reporting lower levels of delinquent behaviour were more likely to stay in the study) and sex (females were more likely than males to remain in the study), but not by zygosity and internalizing symptoms.

\section{Phenotypic analyses}

Phenotypic analyses were conducted using Stata (StataCorp, 2007). Concurrent (time 2) and longitudinal (across times 1-3) associations between variables were first explored using full and partial correlations. Partial correlations allowed investigating unique associations between two variables over and above associations accounted for by other variables (e.g. unique association between attributional style and depression symptoms controlling for hopelessness and anxiety symptoms). Next, the Sobel-Goodman test was used to test whether hopelessness mediates the relationship between attributional style and depression, concurrently and across time (Preacher \& Hayes, 2004). Bootstrapping was used to obtain confidence intervals. All phenotypic analyses were conducted on untransformed and unregressed variables for comparison with other published samples. Analyses were conducted on a random selection of one twin from each twin pair to ensure the independence of observations.

\section{Twin analyses}

The twin design compares the similarity between monozygotic (sharing 100\% of their genes) and dizygotic (sharing on average $50 \%$ of their segregating genes) twin pairs. Differences in within-pair correlations allows estimations of the influences of additive genetics (A), shared environment (C, factors that contribute to phenotypic similarity between siblings) and non-shared environment ( $\mathrm{E}$, factors that contribute to phenotypic differences between siblings). Quantitative genetic methods are described comprehensively elsewhere (Rijsdijk \& Sham, 2002; Plomin et al. 2013).

Twin models were fitted using OpenMx (Boker et al. 2011) within R (http://www.R-project.org) (TeamRDC, 2010), a structural equation modelling package for genetically informative data. As is standard in model fitting analysis, all variables were regressed for age and sex (McGue \& Bouchard, 1984), and depression at both waves and hopelessness were log transformed. Transformation did not have an impact on the relationship between the variables in a way that would alter interpretation.

Models were fitted using raw data maximum likelihood. The core fit statistic was minus twice the log likelihood (-2LL) of the observations. This is not an overall measure of fit, but provides a relative measure of fit, since differences in -2LL between models are distributed as $\chi^{2}$. To examine the overall fit of the genetic model we compared the -2LL to that of a saturated model (which fully describes data using the maximum number of free parameters, estimating variances, covariances and means for the raw data to get a baseline index of fit). The fit of sub-models was assessed by $\chi^{2}$ difference tests, Akaike's Information Criterion (AIC) and Bayesian Information Criterion, with lower values suggesting a better fit. If the difference between the AIC of two models was $<10$, the more parsimonious model was selected (Wagenmakers \& Farrell, 2004). Information about the precision of parameter estimates was obtained by likelihood-based confidence intervals.

\section{Univariate twin analyses}

Univariate genetic analyses were conducted for all variables. Males and females showed differences in variance on all variables and a scalar was fitted to account for this difference. Qualitative and quantitative sex differences were tested to see whether males and females differ in type and magnitude of genetic and environmental influences, but such differences were not found. The exception was attributional style at time 1, which showed quantitative sex differences, however differences in magnitude were small with 
Table 2. Descriptive statistics and phenotypic correlations: full correlations below diagonal and partial correlations above diagonal

\begin{tabular}{|c|c|c|c|c|}
\hline (a) Descriptive statistics & $N$ (individuals) & Mean (S.D.) & Skew & Cronbach's $\alpha$ \\
\hline Attributional style time 1 & 2562 & $4.30(3.31)$ & -0.50 & 0.61 \\
\hline Attributional style time 2 & 1570 & $4.37(3.50)$ & -0.58 & 0.66 \\
\hline Hopelessness time 2 & 1573 & $3.66(3.25)$ & 1.66 & 0.82 \\
\hline Depression time 2 & 1590 & $6.25(5.33)$ & 1.14 & 0.79 \\
\hline Depression time 3 & 1549 & $6.45(5.73)$ & 1.26 & 0.90 \\
\hline Anxiety time 2 & 1569 & $20.62(12.80)$ & 1.21 & 0.87 \\
\hline Anxiety time 3 & 1552 & $25.06(14.88)$ & 1.18 & 0.94 \\
\hline (b) Concurrent correlations & Attributional style time 2 & Hopelessness time 2 & Depression time 2 & Anxiety time 2 \\
\hline Attributional style time 2 & - & $-0.31(-0.37$ to -0.25$)$ & $-0.23(-0.29$ to -0.16$)$ & $-0.04(-0.11$ to 0.03$)$ \\
\hline Hopelessness time 2 & $-0.47(-0.52$ to -0.42$)$ & - & $0.27(0.21$ to 0.33$)$ & 0.07 (0.00 to 0.14$)$ \\
\hline Depression time 2 & $-0.46(-0.51$ to -0.40$)$ & $0.50(0.45$ to 0.55$)$ & - & 0.51 (0.48 to 0.56$)$ \\
\hline Anxiety time 2 & $-0.32(-0.38$ to -0.26$)$ & $0.36(0.30$ to 0.42$)$ & 0.61 (0.57 to 0.65$)$ & - \\
\hline (c) Longitudinal correlations & Attributional style time 1 & Hopelessness time 2 & Depression time 3 & Anxiety time 3 \\
\hline Attributional style time 1 & - & $-0.26(-0.33$ to -0.19$)$ & $-0.09(-0.17$ to -0.01$)$ & $-0.03(-0.11$ to 0.05$)$ \\
\hline Hopelessness time 2 & $-0.28(-0.35$ to -0.21$)$ & - & 0.17 (0.09 to 0.25$)$ & 0.08 (0.00 to 0.16$)$ \\
\hline Depression time 3 & $-0.23(-0.30$ to -0.15$)$ & 0.33 (0.26 to 0.40$)$ & - & 0.59 (0.54 to 0.64$)$ \\
\hline Anxiety time 3 & $-0.20(-0.27$ to -0.12$)$ & $0.27(0.20$ to 0.34$)$ & $0.62(0.57$ to 0.67$)$ & - \\
\hline
\end{tabular}

S.D., Standard deviation.

95\% Confidence intervals (CIs) are presented in parentheses. CIs not inclusive of zeros indicate significant correlations. Non-overlapping CIs mean significant difference between the values.

Partial correlations between two variables (e.g. attributional style and hopelessness) controlled for the associations with the other two variables (e.g. depression and anxiety symptoms).

Higher scores indicate more positive attributional style, greater helplessness and greater depression and anxiety symptoms. 
overlapping $95 \%$ confidence intervals $\left[\mathrm{A}_{\mathrm{M}}=0.38(95 \%\right.$ CI $0.25-0.49)$ v. $\mathrm{A}_{\mathrm{F}}=0.49(95 \% \mathrm{CI} 0.39-0.58)$ and $\mathrm{E}_{\mathrm{M}}=$ $0.49(95 \%$ CI $0.39-0.58) \quad$ v. $\mathrm{E}_{\mathrm{F}}=0.51 \quad(95 \%$ CI $0.42-$ 0.61)] and for simplicity homotypic models are presented. Finally, comparisons indicated that covariances, means and variances could be equated across dizygotic twins and singleton siblings for all variables, thus siblings were modelled alongside twins in the analyses.

\section{Multivariate twin analyses}

First, a one-factor independent pathway model was fitted to examine the genetic and environmental overlap on the three variables (Fig. 1a). The model allows one set of common $\left(\mathrm{A}_{\mathrm{C}}\right.$, and $\left.\mathrm{E}_{\mathrm{C}}\right)$ and variable-specific $\left(A_{S}\right.$, and $\left.E_{S}\right)$ genetic and environmental influences on each variable. The model tests whether there is a single set of common aetiological factors that influence attributional style, hopelessness and depression symptoms, accounting for their associations, in addition to variable-specific factors.

Next, the Cholesky decomposition (Fig. 1b) was used to examine whether there are any genetic and environmental influences shared between hopelessness and depression when accounting for the genetic overlap with attributional style. The Cholesky decomposition assumes three distinct sets of genetic and environmental influences on a variable at each time point. A1 and $\mathrm{E} 1$ are influences on the first variable (paths $\mathrm{a} 1_{1}$ and $\mathrm{e}_{1}$ ) that can also influence the remaining two variables (paths $\mathrm{a}_{2-3}$ and $\mathrm{e}_{2-3}$ ). A2 and E2 influence the second variable (paths $\mathrm{a} 2_{2}$ and $\mathrm{e} 2_{2}$ ) and can also influence the third variable over and above the influences accounted for by $\mathrm{A} 1$ and $\mathrm{E} 1$ (paths $\mathrm{a} 2{ }_{3}$ and $\mathrm{e} 22_{3}$ ). A3 and E3 are unique, residual influences specific to the third variable only (paths $\mathrm{a} 3_{3}$ and $\mathrm{e} 3_{3}$ ).

Both multivariate models were fitted concurrently at time 2, and longitudinally at times $1-3$. Although any ordering of variables explained the variancecovariance matrix between the variables equally well, the order of variables was based on the hopelessness theory of depression. Longitudinal models allowed investigating how aetiological influences operated across development, reflecting the developmental predictions of the theory. However, in addition to variable-specific influences, influences at later time points can also reflect age-specific genetic and environmental innovation that characterizes adolescence (Hannigan et al. in press; Kendler et al. 2008; Waszczuk et al. 2016). Concurrent models allowed investigating variablespecific influences without the confounding effect of genetic and environmental innovation across time.

\section{Results}

\section{Phenotypic results}

Attributional style and hopelessness were moderately associated with internalizing symptoms (Table 2), both concurrently $(r=-0.47$ and 0.50 with depression, $r=-0.32$ and 0.36 with anxiety, respectively) and longitudinally $(r=0 .-0.23$ and 0.33 with depression, $r=-0.20$ and 0.27 with anxiety, respectively). However, partial correlations indicated that when controlling for depression symptoms, neither attributional style nor hopelessness remained significantly associated with anxiety symptoms. Conversely, both maladaptive cognitive styles were uniquely associated with depression symptoms after controlling for anxiety, both concurrently and across time $\left(r_{\mathrm{p}}=-23\right.$ and -0.09 for attributional style and $r_{\mathrm{p}}=.27$ and 0.17 for hopelessness, respectively). Given the lack of unique association between both maladaptive styles and anxiety symptoms, only depression was taken forward to further analyses.

Mediation analyses revealed that hopelessness partially mediated the relationship between attributional style and depression symptoms (Fig 2). Specifically, hopelessness mediated about $37 \%$ of this relationship concurrently (total effect $=-0.71$, indirect effect via hopelessness $=-0.26$ ) (Fig. $2 a$ ), and about 38\% longitudinally (total effect $=-0.37$, indirect effect via hopelessness $=-0.14$ ) (Fig. 2b).

\section{Twin modelling results}

Model fit statistics for comparisons to saturated models, and testing whether parameters can be dropped, are presented in Supplementary Table S1. Model fit statistics corroborate AE models and in the full models $C$ estimates are very small. However, for completeness full ACE models are presented in the Supplementary material (Tables S2, S3). Dropping C from the models did not have impact on the interpretation of the results. The associations between attributional style and depression symptoms, including univariate ACE results for these variables, have been reported before (Lau et al. 2006; Lau \& Eley, 2008; Zavos et al. 2010).

Univariate results revealed that hopelessness was moderately heritable ( $\mathrm{A}=0.37,95 \%$ CI $0.28-0.47$ ), with remaining variance accounted for by non-shared environmental influences ( $E=0.63,95 \%$ CI 0.53-0.73). Attributional style and depression symptoms were also moderately heritable and univariate results for these variables have been presented before (Lau et al. 2006; Lau \& Eley, 2008; Zavos et al. 2010).

Independent pathway models examined common (i.e. influencing all three variables) and variablespecific genetic and shared environmental influences 
(a)

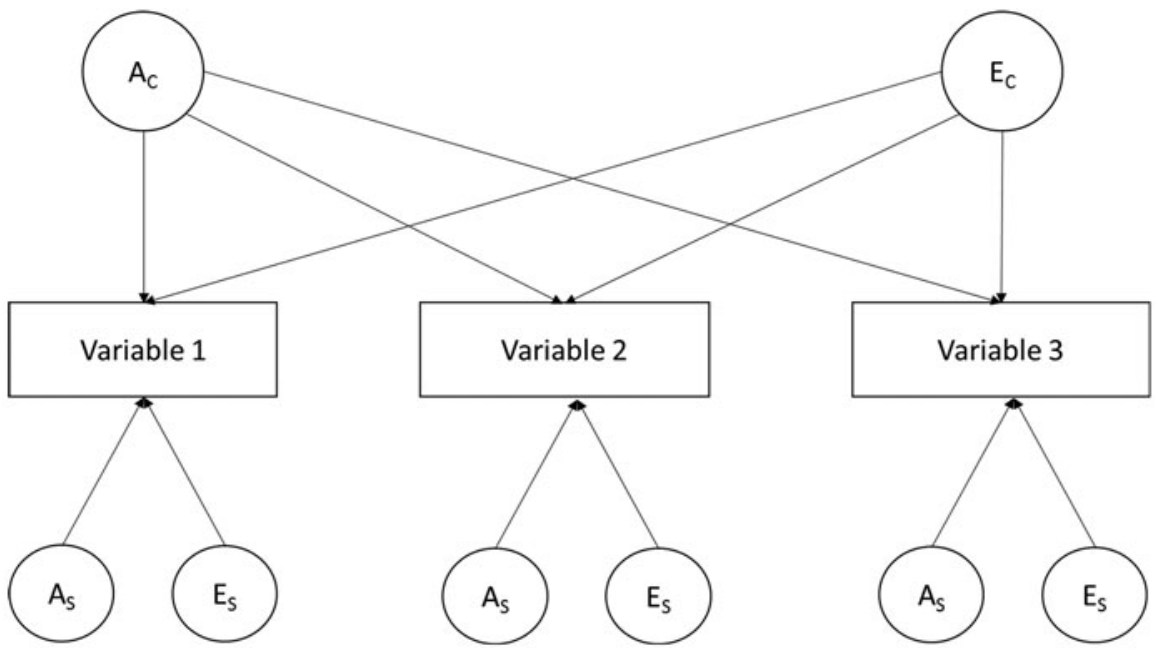

(b)

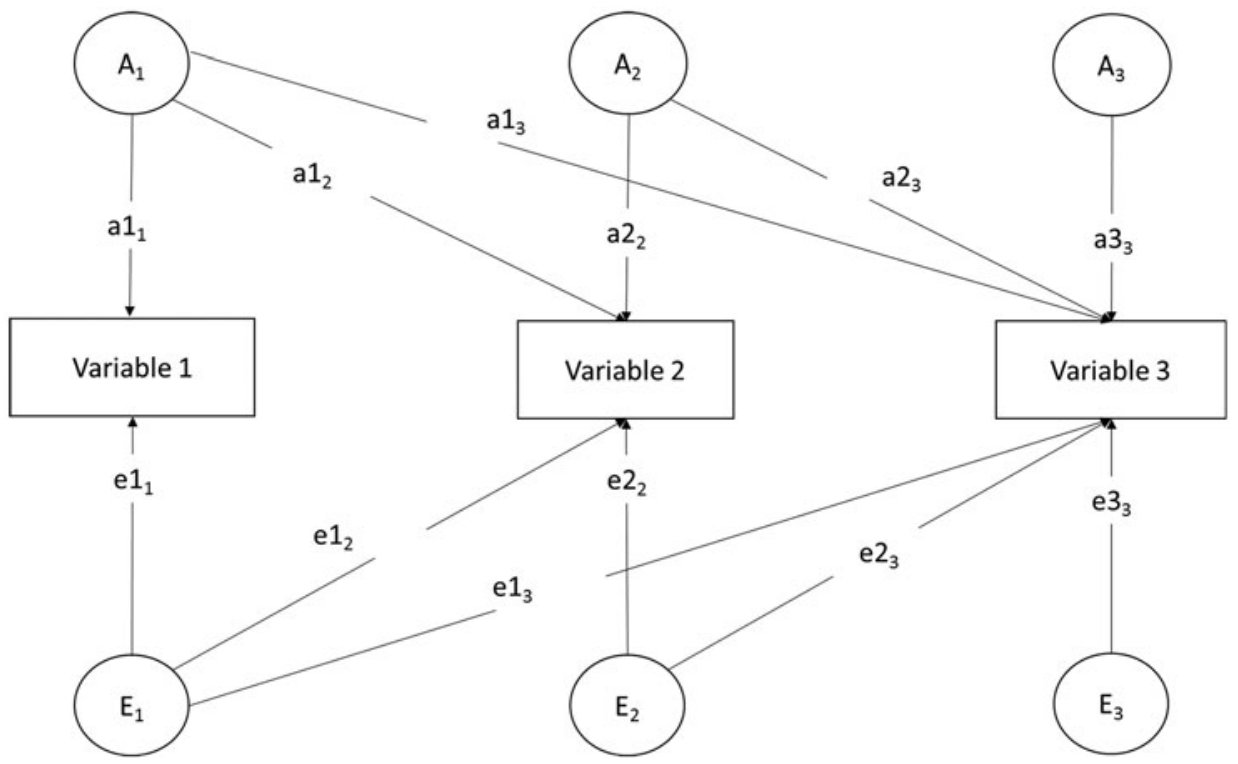

Fig. 1. (a) Independent pathways model, (b) Cholesky decomposition. AE models are presented for clarity. Model fit statistics corroborated AE models and in the full models $\mathrm{C}$ estimates were very small.

on attributional style, hopelessness and depression symptoms. Concurrently, common genetic influences accounted for majority of genetic influences on attributional style and depression $\left(\mathrm{A}_{\mathrm{c}}=0.31\right.$ and 0.30 , accounting for $70 \%$ (95\% CI 49-96) and 64\% (95\% CI 44-90) of total genetic variance in each variable, respectively), and about half genetic influences on hopelessness $\left(A_{c}=0.19\right.$, accounting for $51 \%$ (95\% CI 34-71) of total genetic variance in hopelessness) (Fig. 3a). Common non-shared environmental influences were significant and accounted for about a third of all nonshared environmental influences on variables $\left[\mathrm{E}_{\mathrm{c}}=\right.$ $0.21,0.26$ and 0.11 on attributional style, hopelessness and depression, respectively, accounting for 37\% (95\% CI 21-57), 42\% (95\% CI 25-59) and 20\% (95\% CI 10-33) of total non-shared environmental variance].
All variable-specific influences were significant $\left(\mathrm{A}_{\mathrm{s}}=\right.$ $\left.0.13-0.18, \mathrm{E}_{\mathrm{s}}=0.35-0.42\right)$.

Longitudinally, common genetic influences were the only source of common variance, and accounted for about half of genetic influences in attributional style time $1\left[\mathrm{~A}_{\mathrm{c}}=0.22\right.$, accounting for $51 \%$ (95\% CI 37-67) of total genetic variance in attributional style time 1] and the majority of genetic influences on hopelessness time 2 and depression symptoms time $3\left(\mathrm{~A}_{\mathrm{c}}=0.36\right.$ and 0.30 , accounting for $83 \%(95 \%$ CI $64-100)$ and $77 \%$ (95\% CI 56-100) of total genetic variance in each variable respectively). Furthermore, there were only significant variable-specific genetic influences on attributional style (Fig. 4a). Thus all genetic influence on both hopelessness and depression was common to all three variables. Common non-shared environmental 
(a)

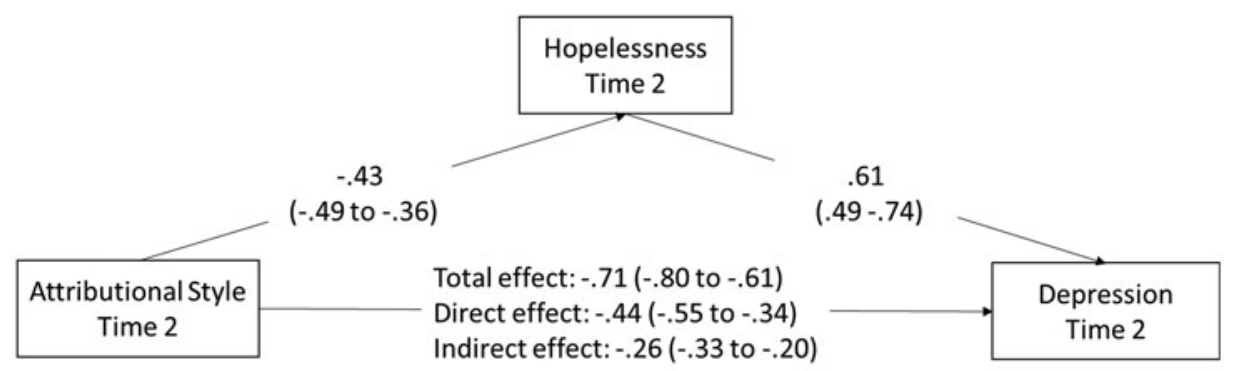

(b)

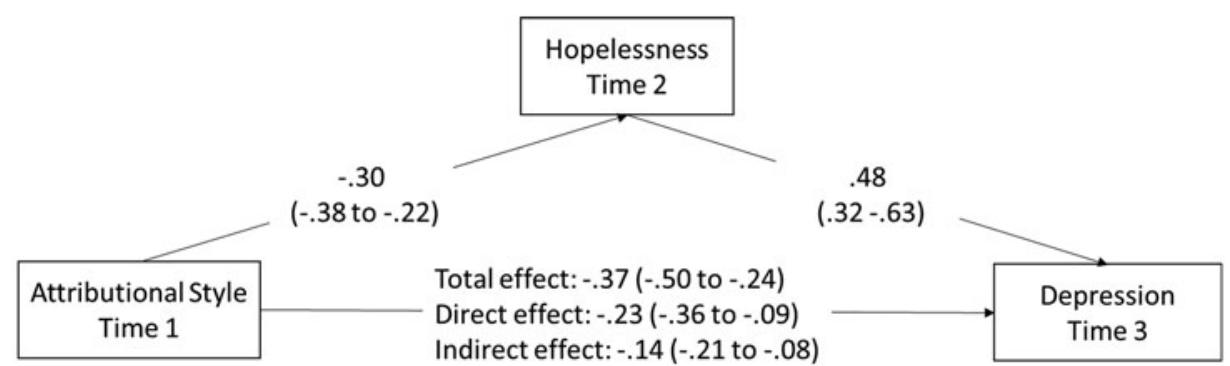

Fig. 2. Mediation analyses results: (a) concurrently at time 2, (b) longitudinally across times 1-3. 95\% Confidence Intervals (CIs) are presented in brackets. CIs not inclusive of zeros indicate significant coefficients. Non-overlapping CIs mean significant difference between the values.

influences did not emerge (for longitudinal independent pathway model with $\mathrm{E}_{\mathrm{c}}$ see Supplementary Table S2, and for model fit comparisons see Supplementary Table S1 note), instead, all non-shared environmental influences were large and variablespecific $\left(E_{\mathrm{s}}=0.57-0.61\right)$.

Cholesky decompositions examined whether there are any genetic and environmental influences shared between hopelessness and depression when accounting for the genetic overlap with attributional style. Both concurrent and longitudinal Cholesky decompositions indicate that after accounting for genetic influences shared with attributional style, there were no significant additional genetic associations between hopelessness and depression (standardized path $\mathrm{a} 2_{3}$ was non-significant in Figs $3 b$ and $4 b$ ). Although non-shared environmental influences were largely variable-specific, when accounting for non-shared environmental influences shared with attributional style, there was a small but significant non-shared environmental association between hopelessness and depression in concurrent analyses (standardized path $\left.\mathrm{e} 2_{3}=0.02\right)$.

\section{Discussion}

This study is the first to investigate the hopelessness theory of depression from an aetiological perspective, both within and across time-points during adolescence and into young adulthood. Phenotypic results supported the theory, as hopelessness partially mediated the relationship between attributional style and depression symptoms, and both maladaptive cognitive styles were unique to depression and not to anxiety (the latter phenotype was therefore dropped from twin analyses). Twin modelling results revealed that a set of common genetic influences largely accounted for the association between attributional style, hopelessness and depression symptoms, indicating shared genetic liability to maladaptive cognitions and depression underpinning the hopelessness theory of depression.

\section{Aetiology of hopelessness theory of depression}

Current phenotypic results indicate that hopelessness partially mediates the association between attributional style and depression symptoms, both concurrently and across development, as predicted by the hopelessness theory of depression. This is in line with some (Alloy \& Clements, 1998), but not all (Abela, 2001; Hankin et al. 2001) previous studies. Furthermore, although prospective longitudinal results indicated that about a third of the association between early attributional style and later depression was mediated via hopelessness, both attributional style and hopelessness were also uniquely associated with depression symptoms, indicating that they may be independent cognitive risk factors for developing depression in adolescence. 
(a)

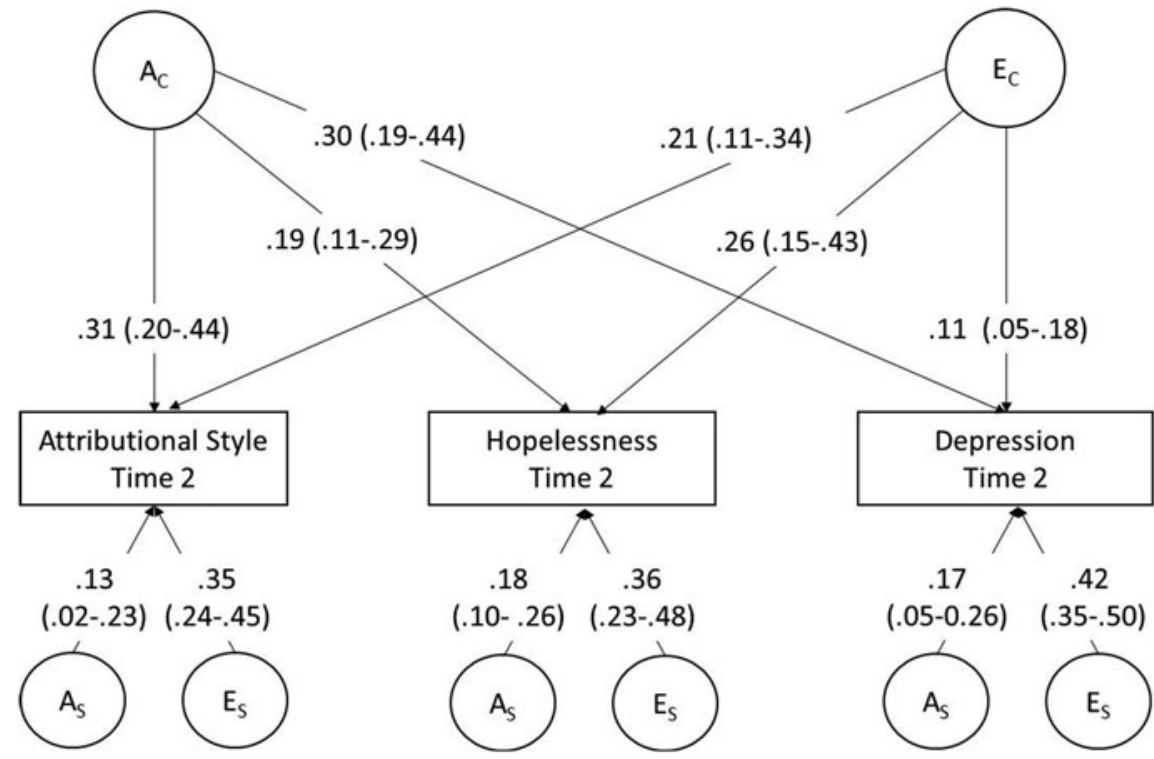

(b)

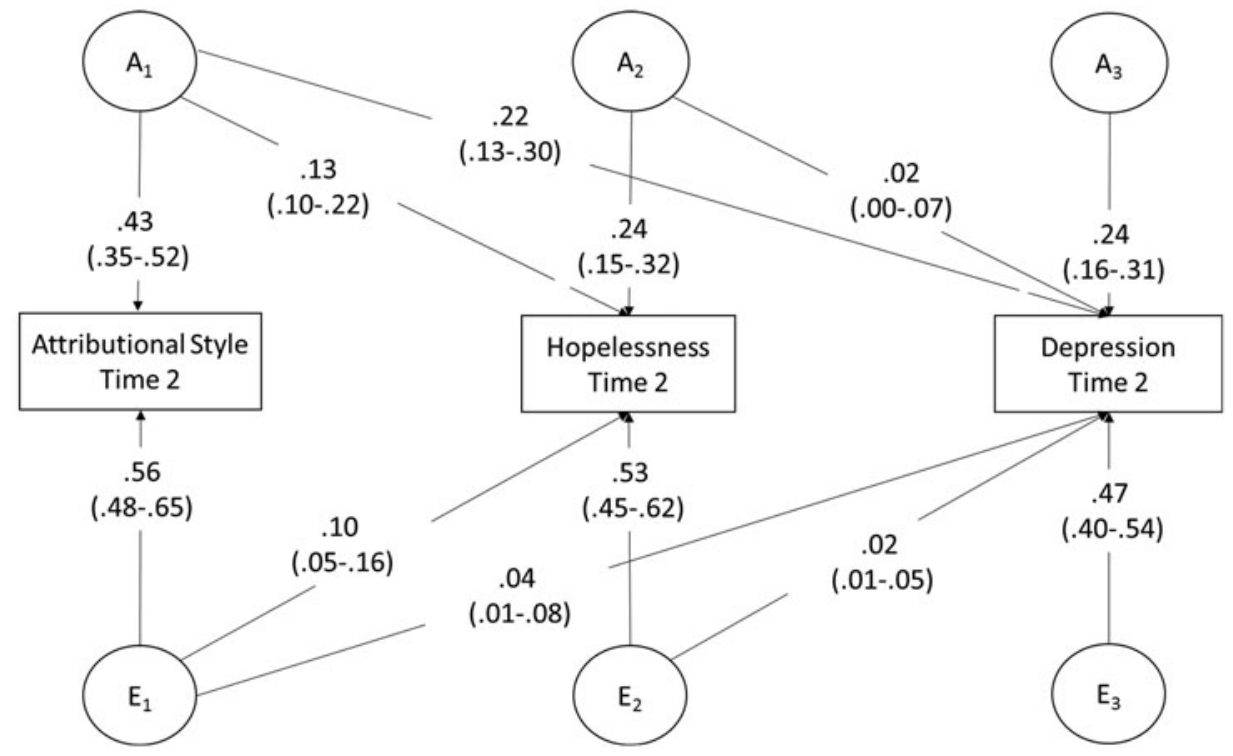

Fig. 3. Concurrent multivariate results: (a) Independent pathways model, $(b)$ Cholesky decomposition. All paths are squared. Square root of these values should be taken to obtain variance path.

Univariate twin modelling results highlighted the role of both genetic and environmental influences in the aetiology of adolescent hopelessness. The current heritability estimate was moderate, in line with the previous estimate of heritability of a composite hopelessness and guilt trait in adults (Jang et al. 2004), but extends previous research by using a more comprehensive, validated measure of hopelessness and expands understanding of its aetiology to a novel developmental period.

Most of the genetic influences on each of the two maladaptive cognitions and depression symptoms were shared concurrently and across development. Furthermore, there were no shared genetic influences between hopelessness and depression over and above genetic influences shared with attributional style. Thus, as expected, the association between maladaptive cognitions and depression was explained largely by underlying genetic liability, in line with the generalist genes hypothesis (Eley, 1997). The results are also in agreement with previous findings that associations between many different cognitive biases and internalizing problems are largely due to shared genetic influences (Lau \& Eley, 2008; Zavos et al. 2010; Chen \& Li, 2013; Moore et al. 2013; Waszczuk et al. 2013; Brown et al. 2014; Lau et al. 2014). The results are suggestive of developmentally stable biological pathways underpinning the hopelessness theory of depression. 
(a)

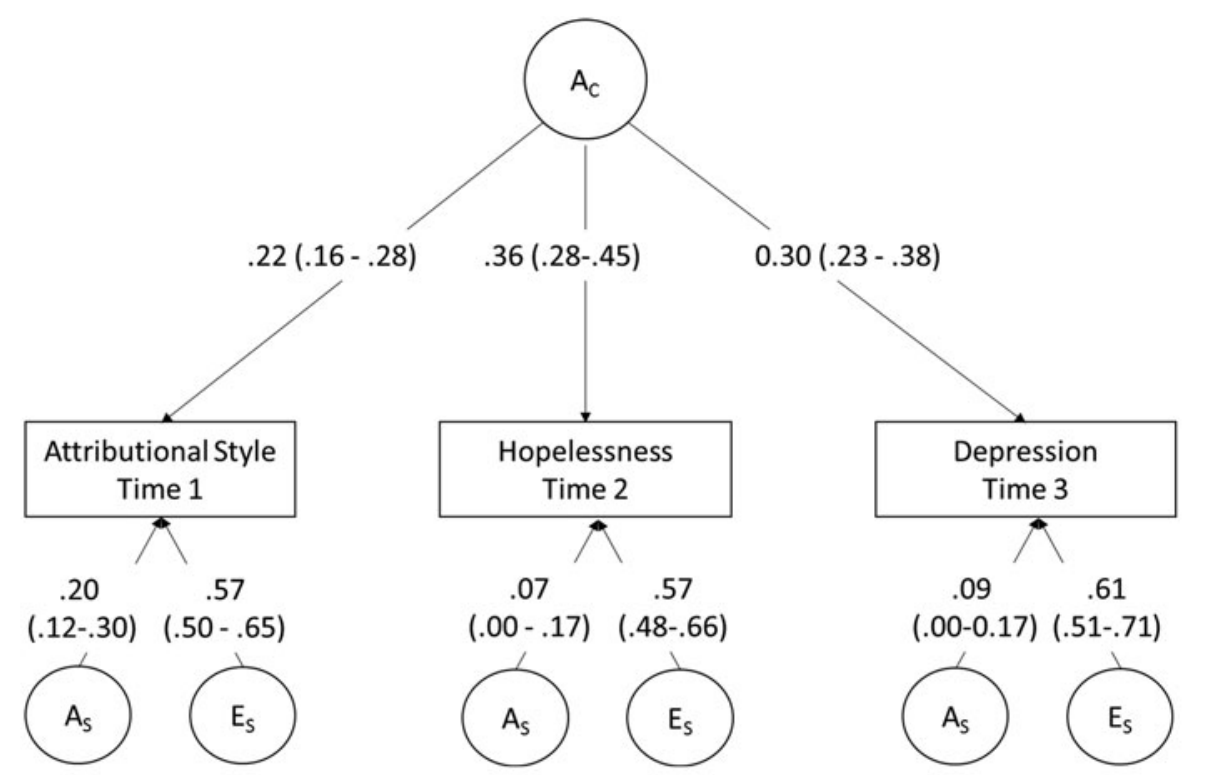

(b)

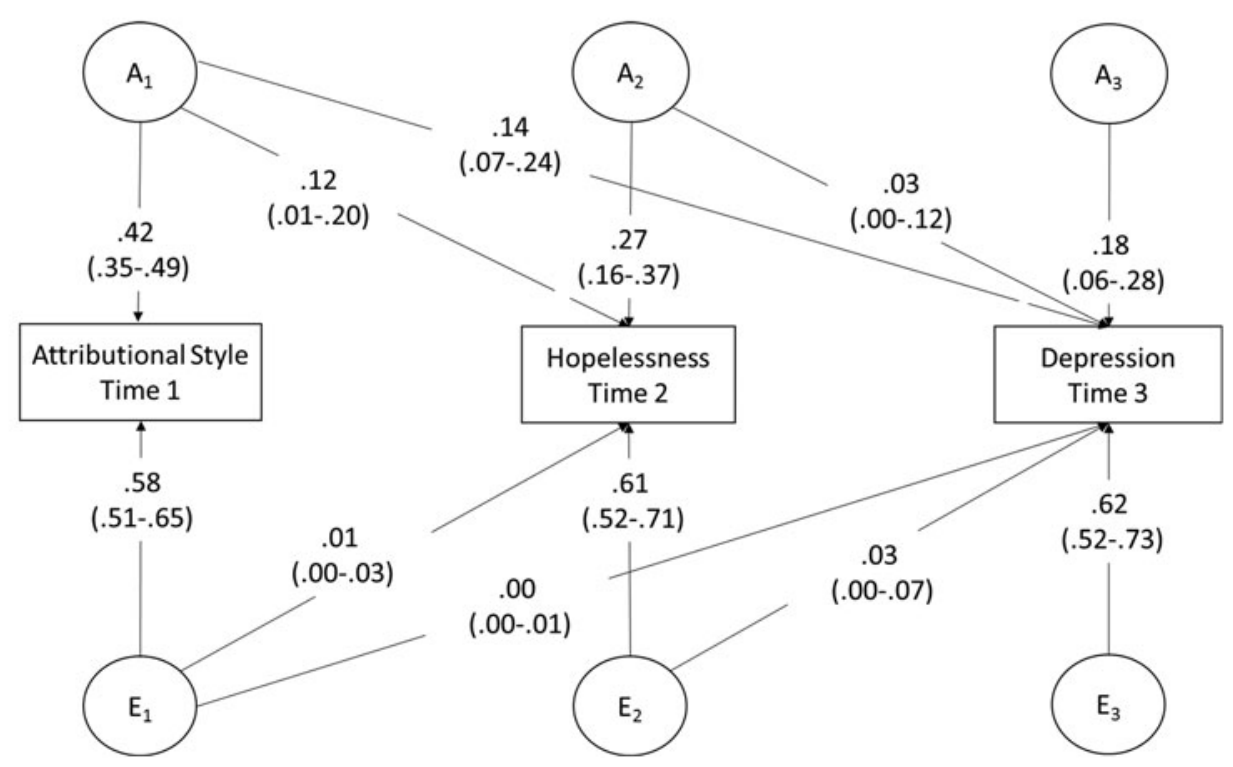

Fig. 4. Longitudinal multivariate results: (a) Independent pathways model, (b) Cholesky decomposition. All paths are squared. Square root of these values should be taken to obtain variance path.

Evidence for shared genetic effects has implications for molecular genetic studies, supporting the argument that including cases with a range of depression-related phenotypes would lead to increasing power to detect shared susceptibility loci (Hettema et al. 2015). It also suggests that the role of specific genes in the aetiology of internalizing symptoms and maladaptive cognition should be investigated as it might be possible to combine the genetic markers to create polygenic risk scores to predict an individual's vulnerability to depression (Demirkan et al. 2011).

Conversely, non-shared environmental influences were largely trait-specific, especially in longitudinal analyses. This indicates that environmental influences contribute to differences between cognitive vulnerabilities and depression, possibly explaining some of the phenotypic specificity observed. However, a significant common non-shared environmental factor suggests that it might be possible to identify environmental influences that contribute to the hopelessness theory of depression. In line with the theory, these could be negative life events that interact with attributional style in a diathesis-stress manner. Future studies should aim to identify these specific environmental influences to inform targeted clinical and resilience interventions in adolescence. Nonetheless, this common non-shared environmental factor might also to some extent reflect time-specific measurement error, as it does not replicate in the longitudinal analyses. 


\section{Cognitive specificity}

Evidence for phenotypic specificity in associations between attributional style, hopelessness and depression, and unique environmental influences acting on these symptoms, has implications for therapeutic interventions. Furthermore, identifying disorder-specific maladaptive cognitions, and also those shared between co-morbid disorders such as depression and anxiety, could continue to inform the tailoring of CBT programmes to a given diagnosis. Current findings indicate that both attributional style and hopelessness are independently and uniquely associated with depression symptoms, but not with anxiety symptoms in adolescence. This is in line with previous research finding that hopelessness is a maladaptive cognition specific to depression (Beck et al. 2001, 2006; Alloy et al. 2012; Hendriks et al. 2014). Conversely, the finding that attributional style is unique to depression supports some previous studies in adults and children (Rodriguez \& Pehi, 1998; Hankin et al. 2004; Brozina \& Abela, 2006), but does not support the view, based largely on adult literature, that attributional style is a transdiagnostic cognitive risk factor for both depression and anxiety (Luten et al. 1997; Alloy et al. 2012). Taken together, these results indicate that negative thoughts and interpretations about the present and future events constitute central and unique cognitive content in adolescent depression, in line with cognitive specificity hypothesis (Beck \& Perkins, 2001). This supports the clinical evidence that modifying attributional style and hopelessness in CBT prevents and reduces adolescent depression, as well as other important depression-related symptoms such as suicidality (Brent et al. 1998; Voelz et al. 2003; Stanley et al. 2009). However, our findings also imply that targeting attributional style and hopelessness may not be as effective in reducing adolescent anxiety symptoms. Future research should aim to explore the unique and transdiagnostic content of depressive cognitions in more detail by combining multiple cognitive distortions within a single study.

\section{Limitations}

The genetically-informative, representative sample and multiple time points are strengths of the study. However, a number of limitations are noteworthy. First, it was beyond the scope of the current study to investigate all aspects of the hopelessness theory of depression, such as the generally supported diathesis-stress interaction between negative life events and attributional style (Abela, 2001; Hankin et al. 2001; Abela \& Sarin, 2002). Furthermore, Abramson et al. (1989) posited that the theory is specific to 'hopelessness depression', however the distinction of this depression subtype from major depression is debated (Alloy \& Clements, 1998), and the theory has generally been studied with broad measures of depression. Future research should explore phenotypic and aetiological associations between different dimensions of depression, attributional style and hopelessness within the context of the theory, which was beyond the scope of the current study. It should also investigate whether there are bidirectional associations between attributional style, hopelessness and depression (Zavos et al. 2010). Second, our analyses used self-report internalizing symptoms. Results should be replicated in clinical samples and using lifetime diagnostic interviews. However, symptoms of internalizing disorders are important markers of psychopathology (Pickles et al. 2001; Fergusson et al. 2005; Balázs et al. 2013). Common psychiatric disorders are now considered to be the extremes of quantitative traits (Plomin et al. 2009; Insel et al. 2010) and there is evidence that differently defined internalizing problems have the same aetiology (Kendler et al. 1987, 1992a, b). Nonetheless, reliance on self-report data may be associated with shared method variance that could inflate the correlations. Third, there was attrition in the samplealthough not for internalizing symptoms. Attrition bias might complicate estimation of trait prevalence; however it is unlikely to affect the estimation of between trait associations (Wolke et al. 2009). Last, there are limitations inherent to the twin design, discussed comprehensively elsewhere (Plomin et al. 2013). These have minimal and contrasting effects on parameter estimates which should be taken as indicative rather than absolute.

\section{Conclusions}

The current study is the first to study the aetiological underpinnings of the hopelessness theory of depression, demonstrating that associations between attributional style, hopelessness and depression symptoms are largely due to shared genetic liability, suggesting developmentally stable biological pathways underpinning this influential theory. Furthermore, both attributional style and hopelessness were not related to anxiety, thus constituted unique cognitive content in depression. The results inform molecular genetics research and treatment approaches, as identifying specific cognitions in depression can inform the design of more precise clinical interventions for this disorder across development.

\section{Supplementary material}

For supplementary material accompanying this paper visit http://dx.doi.org/10.1017/S0033291716000489. 


\section{Acknowledgements}

G1219 study was supported by a Medical Research Council Training Fellowship (G81/343) and a Career Development Award (G120/635) given to Thalia C. Eley. Waves 1-3 of G1219 were also funded by the W T Grant Foundation, the University of London Central Research fund and wave 4 was supported by the Economic and Social Research Council (RES000-22-2206), the Institute of Social Psychiatry (06/0711) to Alice M. Gregory who was supported by a Leverhulme Research Fellowship (RF/2/RFG/2008/ 0145). Monika A. Waszczuk was supported by a Ph. D. studentship funded by the Alexander von Humboldt Foundation. This study presents independent research partly funded by the National Institute for Health Research (NIHR) Biomedical Research Centre at South London and Maudsley NHS Foundation Trust and King's College London. The views expressed in this article are those of the authors and not necessarily those of the NHS, the NIHR, or the Department of Health. Monika A. Waszczuk had full access to all of the data in the study and takes responsibility for the integrity of the data and the accuracy of the data analysis. We thank the families for their participation as well as numerous staff and students from the Social Genetic Developmental Psychiatry Centre, Institute of Psychiatry, London and Goldsmiths, University of London.

\section{Declaration of Interest}

None.

\section{References}

AACAP (2007). Practice parameter for the assessment and treatment of children and adolescents with anxiety disorders. Journal of the American Academy of Child and Adolescent Psychiatry 46, 267-283.

Abela JR (2001). The hopelessness theory of depression: a test of the diathesis-stress and causal mediation components in third and seventh grade children. Journal of Abnormal Child Psychology 29, 241-254.

Abela JR, Sarin S (2002). Cognitive vulnerability to hopelessness depression: a chain is only as strong as its weakest link. Cognitive Therapy and Research 26, 811-829.

Abramson LY, Metalsky GI, Alloy LB (1989). Hopelessness depression: a theory-based subtype of depression.

Psychological Review 96, 358.

Abramson LY, Seligman MEP, Teasdale JD (1978). Learned helplessness in humans: critique and reformulation. Journal of Abnormal Psychology 87, 49-74.

Ahrens AH, Haaga DA (1993). The specificity of attributional style and expectations to positive and negative affectivity, depression, and anxiety. Cognitive Therapy and Research 17, 83-98.
Alloy LB, Black SK, Young ME, Goldstein KE, Shapero BG, Stange JP, Boccia AS, Matt LM, Boland EM, Moore LC (2012). Cognitive vulnerabilities and depression versus other psychopathology symptoms and diagnoses in early adolescence. Journal of Clinical Child and Adolescent Psychology 41, 539-560.

Alloy LB, Clements CM (1998). Hopelessness theory of depression: tests of the symptom component. Cognitive Therapy and Research 22, 303-335.

Angold A, Costello EJ, Erkanli A (1999). Co-morbidity. Journal of Child Psychology and Psychiatry 40, 57-87.

Angold A, Costello EJ, Messer SC, Pickles A, Winder F, Silver D (1995). The development of a short questionnaire for use in epidemiological studies of depression in children and adolescents. International Journal of Methods in Psychiatric Research 5, 1-12.

Balázs J, Miklósi M, Keresztény Á, Hoven CW, Carli V, Wasserman C, Apter A, Bobes J, Brunner R, Cosman D (2013). Adolescent subthreshold-depression and anxiety: psychopathology, functional impairment and increased suicide risk. Journal of Child Psychology and Psychiatry 54, 670-677.

Beck AT (2008). The evolution of the cognitive model of depression and its neurobiological correlates. American Journal of Psychiatry 165, 969-977.

Beck AT, Weissman A, Lester D, Trexler L (1974). The measurement of pessimism: the hopelessness scale. Journal of Consulting and Clinical Psychology 42, 861.

Beck AT, Wenzel A, Riskind JH, Brown G, Steer RA (2006). Specificity of hopelessness about resolving life problems: another test of the cognitive model of depression. Cognitive Therapy and Research 30, 773-781.

Beck R, Perkins TS (2001). Cognitive content-specificity for anxiety and depression: a meta-analysis. Cognitive Therapy and Research 25, 651-663.

Beck R, Perkins TS, Holder R, Robbins M, Gray M, Allison SH (2001). The cognitive and emotional phenomenology of depression and anxiety: are worry and hopelessness the cognitive correlates of NA and PA? Cognitive Therapy and Research 25, 829-838.

Birmaher B, Brent DA, Chiappetta L, Bridge J, Monga S, Baugher M (1999). Psychometric properties of the screen for child anxiety related emotional disorders (SCARED): a replication study. Journal of the American Academy of Child \& Adolescent Psychiatry 38, 1230-1236.

Boker S, Neale M, Maes H, Wilde M, Spiegel M, Brick T, Spies J, Estabrook R, Kenny S, Bates T (2011). OpenMx: an open source extended structural equation modeling framework. Psychometrika 76, 306-317.

Brent DA, Kolko DJ, Birmaher B, Baugher M, Bridge J, Roth C, Holder D (1998). Predictors of treatment efficacy in a clinical trial of three psychosocial treatments for adolescent depression. Journal of the American Academy of Child and Adolescent Psychiatry 37, 906-914.

Brewin CR (1996). Theoretical foundations of cognitive-behavior therapy for anxiety and depression. Annual Review of Psychology 47, 33-57.

Brown HM, Waszczuk MA, Zavos HMS, Trzaskowski M, Gregory AM, Eley TC (2014). Cognitive content-specificity 
in anxiety and depressive disorder symptoms: a twin study of cross-sectional associations with anxiety sensitivity dimensions across development. Psychological Medicine 44, 3469-3480.

Brozina K, Abela JR (2006). Symptoms of depression and anxiety in children: specificity of the hopelessness theory. Journal of Clinical Child and Adolescent Psychology 35, 515-527.

Chen J, Li X (2013). Genetic and environmental influences on adolescent rumination and its association with depressive symptoms. Journal of Abnormal Child Psychology 41, 12891298.

Chorpita BF, Yim L, Moffitt C, Umemoto LA, Francis SE (2000). Assessment of symptoms of DSM-IV anxiety and depression in children: a revised child anxiety and depression scale. Behaviour Research and Therapy 38, 835-855.

Cole DA, Ciesla JA, Dallaire DH, Jacquez FM, Pineda AQ, LaGrange B, Truss AE, Folmer AS, Tilghman-Osborne C, Felton JW (2008). Emergence of attributional style and its relation to depressive symptoms. Journal of Abnormal Psychology 117, 16.

Costello EJ, Mustillo S, Erkanli A, Keeler G, Angold A (2003). Prevalence and development of psychiatric disorders in childhood and adolescence. Archives of General Psychiatry 60, 837-844.

Cummings CM, Caporino NE, Kendall PC (2014). Co-morbidity of anxiety and depression in children and adolescents: 20 years after. Psychological Bulletin 140, 816.

Demirkan A, Penninx BW, Hek K, Wray NR, Amin N, Aulchenko YS, Van Dyck R, de Geus EJ, Hofman A, Uitterlinden AG (2011). Genetic risk profiles for depression and anxiety in adult and elderly cohorts. Molecular Psychiatry 16, 773-783.

Dozois DJ, Covin R (2004). The Beck Depression Inventory-II (BDI-II), Beck Hopelessness Scale (BHS), and Beck Scale for Suicide Ideation (BSS). In Comprehensive Handbook of Psychological Assessment (ed. M. Hersen), John Wiley \& Sons Inc.: Hoboken, New Jersey.

Dunn V, Goodyer IM (2006). Longitudinal investigation into childhood-and adolescence-onset depression: psychiatric outcome in early adulthood. The British Journal of Psychiatry 188, 216-222.

Eley TC (1997). General genes: a new theme in developmental psychopathology. Current Directions in Psychological Science 6, 90-95.

Fergusson DM, Horwood LJ, Ridder EM, Beautrais AL (2005). Subthreshold depression in adolescence and mental health outcomes in adulthood. Archives of General Psychiatry 62, 66-72.

Field AP, Lester KJ (2010). Is there room for 'development' in developmental models of information processing biases to threat in children and adolescents? Clinical Child and Family Psychology Review 13, 315-332.

Ford T, Goodman R, Meltzer H (2003). The British Child and Adolescent Mental Health Survey 1999: the prevalence of DSM-IV disorders. Journal of the American Academy of Child and Adolescent Psychiatry 42, 1203-11.

Gregory AM, Buysse DJ, Willis TA, Rijsdijk FV, Maughan B, Rowe R, Cartwright S, Barclay NL, Eley TC (2011).
Associations between sleep quality and anxiety and depression symptoms in a sample of young adult twins and siblings. Journal of Psychosomatic Research 71, 250-255.

Gregory AM, Caspi A, Moffitt TE, Koenen K, Eley TC, Poulton R (2007). Juvenile mental health histories of adults with anxiety disorders. American Journal of Psychiatry 164, 301-308.

Hankin BL (2008). Cognitive vulnerability-stress model of depression during adolescence: investigating depressive symptom specificity in a multi-wave prospective study. Journal of Abnormal Child Psychology 36, 999-1014.

Hankin BL, Abramson LY, Miller N, Haeffel GJ (2004). Cognitive vulnerability-stress theories of depression: examining affective specificity in the prediction of depression versus anxiety in three prospective studies. Cognitive Therapy and Research 28, 309-345.

Hankin BL, Abramson LY, Moffitt TE, Silva A, McGee R, Angell KE (1998). Development of depression from preadolescence to young adulthood: emerging gender differences in a 10-year longitudinal study. Journal of Abnormal Psychology 107, 128-140.

Hankin BL, Abramson LY, Siler M (2001). A prospective test of the hopelessness theory of depression in adolescence. Cognitive Therapy and Research 25, 607-632.

Hannigan LJ, Walaker N, Waszczuk MA, McAdams TA, Eley TC (in press). Aetiological influences on stability and change in emotional and behavioural problems across development: a systematic review. Psychopathology Review.

Harrington R, Fudge H, Rutter M, Pickles A, Hill J (1990). Adult outcomes of childhood and adolescent depression. Archives of General Psychiatry 47, 465-473.

Hendriks SM, Licht CM, Spijker J, Beekman AT, Hardeveld F, de Graaf R, Penninx BW (2014). Disorder-specific cognitive profiles in major depressive disorder and generalized anxiety disorder. BMC Psychiatry 14, 96.

Hettema J, Chen X, Sun C, Brown T (2015). Direct, indirect and pleiotropic effects of candidate genes on internalizing disorder psychopathology. Psychological Medicine 45, 2227-2236.

Insel T, Cuthbert B, Garvey M, Heinssen R, Pine DS, Quinn K, Sanislow C, Wang P (2010). Research domain criteria (RDoC): toward a new classification framework for research on mental disorders. American Journal of Psychiatry 167, 748-751.

Jacobs RH, Reinecke MA, Gollan JK, Kane P (2008). Empirical evidence of cognitive vulnerability for depression among children and adolescents: a cognitive science and developmental perspective. Clinical Psychology Review 28, 759-782.

Jang KL, Livesley WJ, Taylor S, Stein MB, Moon EC (2004) Heritability of individual depressive symptoms. Journal of Affective Disorders 80, 125-133.

Joiner TE (2001). Negative attributional style, hopelessness depression and endogenous depression. Behaviour Research and Therapy 39, 139-149.

Katon W, Richardson L, Russo J, McCarty CA, Rockhill C, McCauley E, Richards J, Grossman DC (2010). Depressive symptoms in adolescence: the association with multiple 
health risk behaviors. General Hospital Psychiatry 32, 233-239.

Kendler KS, Gardner CO, Lichtenstein P (2008). A developmental twin study of symptoms of anxiety and depression: evidence for genetic innovation and attenuation. Psychological Medicine 38, 1567-1575.

Kendler KS, Heath AC, Martin NG, Eaves LJ (1987). Symptoms of anxiety and symptoms of depression. Same genes, different environments? Archives of General Psychiatry 44, 451-457.

Kendler KS, Neale MC, Kessler RC, Heath AC, Eaves LJ (1992a). Major depression and generalized anxiety disorder. Same genes, (partly) different environments? Archives of General Psychiatry 49, 716-722.

Kendler KS, Neale MC, Kessler RC, Heath AC, Eaves LJ (1992b). A population-based twin study of major depression in women. The impact of varying definitions of illness. Archives of General Psychiatry 49, 257-266.

Kessler RC, Chiu WT, Demler O, Merikangas KR, Walters EE (2005). Prevalence, severity, and co-morbidity of 12-month DSM-IV disorders in the National Co-morbidity Survey Replication. Archives of General Psychiatry 62, 617-627.

Lau JY, Belli SR, Gregory AM, Eley TC (2014). Interpersonal cognitive biases as genetic markers for pediatric depressive symptoms: twin data from the emotions, cognitions, heredity and outcome (ECHO) study. Development and Psychopathology 26, 1267-1276.

Lau JYF, Eley TC (2008). Attributional style as a risk marker of genetic effects for adolescent depressive symptoms. Journal of Abnormal Psychology 117, 849-859.

Lau JYF, Rijsdijk FV, Eley TC (2006). I think, therefore I am: a twin study of attributional style in adolescents. Journal of Child Psychology and Psychiatry 47, 696-703.

Luten AG, Ralph JA, Mineka S (1997). Pessimistic attributional style: is it specific to depression versus anxiety versus negative affect? Behaviour Research and Therapy 35, 703-719.

McAdams TA, Gregory AM, Rowe R, Zavos H, Barclay NL, Lau JY, Maughan B, Eley TC (2013). The genesis 12-19 (G1219) study: a twin and sibling study of geneenvironment interplay and adolescent development in the UK. Twin Research and Human Genetics 1, 1-10.

McGue M, Bouchard Jr. TJ (1984). Adjustment of twin data for the effects of age and sex. Behavior Genetics 14, 325-343.

Metalsky GI, Joiner TE (1992). Vulnerability to depressive symptomatology: a prospective test of the diathesis-stress and causal mediation components of the hopelessness theory of depression. Journal of Personality and Social Psychology 63, 667.

Miranda R, Mennin DS (2007). Depression, generalized anxiety disorder, and certainty in pessimistic predictions about the future. Cognitive Therapy and Research 31, 71-82.

Moore MN, Salk RH, Van Hulle CA, Abramson LY, Hyde JS, Lemery-Chalfant K, Goldsmith HH (2013). Genetic and environmental influences on rumination, distraction, and depressed mood in adolescence. Clinical Psychological Science 1, 316-322.
Pickles A, Rowe R, Simonoff E, Foley D, Rutter M, Silberg J (2001). Child psychiatric symptoms and psychosocial impairment: relationship and prognostic significance. British Journal of Psychiatry 179, 230-235.

Plomin R, DeFries JC, Knopik VS, Neiderhiser JM (2013). Behavioral Genetics. Worth Publishers: New York.

Plomin R, Haworth CM, Davis OS (2009). Common disorders are quantitative traits. Nature Reviews: Genetics 10, 872-878.

Preacher KJ, Hayes AF (2004). SPSS and SAS procedures for estimating indirect effects in simple mediation models. Behavior Research Methods, Instruments, and Computers 36, 717-731.

Puig-Antich J, Kaufman J, Ryan ND, Williamson DE, Dahl RE, Lukens E, Todak G, Ambrosini P, Rabinovich H, Nelson B (1993). The psychosocial functioning and family environment of depressed adolescents. Journal of the American Academy of Child and Adolescent Psychiatry 32, 244-253.

Reardon JM, Williams NL (2007). The specificity of cognitive vulnerabilities to emotional disorders: anxiety sensitivity, looming vulnerability and explanatory style. Journal of Anxiety Disorders 21, 625-643.

Riglin L, Petrides K, Frederickson N, Rice F (2014). The relationship between emotional problems and subsequent school attainment: a meta-analysis. Journal of Adolescence 37, 335-346.

Rijsdijk FV, Sham PC (2002). Analytic approaches to twin data using structural equation models. Briefings in Bioinformatics 3, 119-133.

Rodriguez CM, Pehi P (1998). Depression, anxiety, and attributional style in a New Zealand sample of children. New Zealand Journal of Psychology 27, 28.

Spence SH (1998). A measure of anxiety symptoms among children. Behaviour Research and Therapy 36, 545-566.

Stanley B, Brown G, Brent DA, Wells K, Poling K, Curry J, Kennard BD, Wagner A, Cwik MF, Klomek AB (2009). Cognitive-behavioral therapy for suicide prevention (CBT-SP): treatment model, feasibility, and acceptability. Journal of the American Academy of Child and Adolescent Psychiatry 48, 1005-1013.

StataCorp (2007). Stata Statistical Software: Release 10. StataCorp LP: College Station, TX.

TeamRDC (2010). R: A Language and Environment for Statistical Computing. R Foundation for Statistical Computing: Vienna, Austria.

Thompson M, Kaslow NJ, Weiss B, Nolen-Hoeksema S (1998). Children's attributional style questionnaire revised: psychometric examination. Psychological Assessment 10, 166-170.

Voelz ZR, Haeffel GJ, Joiner TE, Wagner KD (2003). Reducing hopelessness: the interation of enhancing and depressogenic attributional styles for positive and negative life events among youth psychiatric inpatients. Behaviour Research and Therapy 41, 1183-1198.

Wagenmakers E-J, Farrell S (2004). AIC model selection using Akaike weights. Psychonomic Bulletin \& Review 11, 192-196. 
Waschbusch DA, Sellers DP, LeBlanc M, Kelley ML (2003). Helpless attributions and depression in adolescents: the roles of anxiety, event valence, and demographics. Journal of Adolescence 26, 169-183.

Waszczuk MA, Zavos HMS, Eley TC (2013). Genetic and environmental influences on relationship between anxiety sensitivity and anxiety subscales in children. Journal of Anxiety Disorders 27, 475-484.

Waszczuk MA, Zavos HMS, Gregory AM, Eley TC (2016). The stability and change of etiological influences on depression, anxiety symptoms and their co-occurrence across adolescence and young adulthood. Psychological Medicine 46, 161-175.
Wolke D, Waylen A, Samara M, Steer C, Goodman R, Ford T, Lamberts K (2009). Selective drop-out in longitudinal studies and non-biased prediction of behaviour disorders. The British Journal of Psychiatry 195, 249-256.

Young MA, Halper IS, Clark DC, Scheftner W, Fawcett J (1992). An item-response theory evaluation of the beck hopelessness scale. Cognitive Therapy and Research 16, 579587.

Zavos H, Rijsdijk FV, Gregory AM, Eley TC (2010). Genetic influences on the cognitive biases associated with anxiety and depression symptoms in adolescents. Journal of Affective Disorders 124, 45-53. 